\title{
Small non-coding RNA profile in anaphylaxis
}

Emilio Nuñez-Borque ${ }^{1}$, Sergio Fernández-Bravo ${ }^{1}$, Diana Betancor ${ }^{2}$, Ebrahim Mohammed Al Washali ${ }^{3}$, Pablo Rodriguez del Rio ${ }^{4}$, Jose Julio Laguna ${ }^{5}$, and Vanesa Esteban ${ }^{1}$

${ }^{1}$ Instituto de Investigación Sanitaria de la Fundación Jiménez Díaz

${ }^{2}$ Hospital Universitario Fundación Jiménez Díaz

${ }^{3}$ Universidad Complutense de Madrid Facultad de Farmacia

${ }^{4}$ Hospital Infantil Universitario Niño Jesús

${ }^{5}$ Hospital Central de la Cruz Roja

May 15, 2020

\section{Hosted file}

Letter_sRNA_Nu \selectlanguage\{ngerman\}ñez-Borque.pdf available at https://authorea.com/users / 322519/articles/451467-small-non-coding-rna-profile-in-anaphylaxis

Figure 1

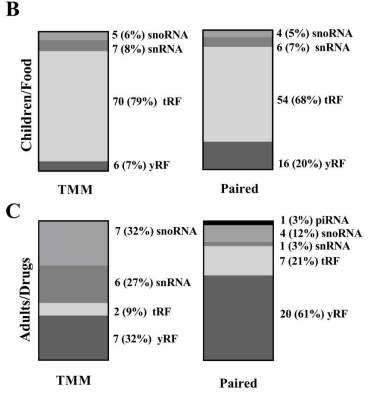

A

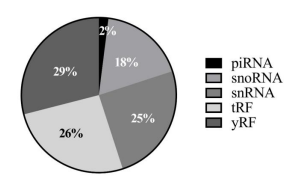

